\title{
PENENTUAN ZONASI DAERAH RAWAN BENCANA LONGSOR STUDI KASUS DI KECAMATAN TUMPANG, KABUPATEN MALANG
}

\author{
Mohammad Reza ${ }^{1}$, Ghestiar Kharisma Kusumo ${ }^{2}$, Mita Nur Bulan Sari ${ }^{3}$, \\ Alisya Fahza Nur Rahmah ${ }^{4}$, Tasya Almira Syah Putri ${ }^{5}$, Yohanes Kurnia Natalino ${ }^{6}$, \\ Muhammad Ilham ${ }^{7}$ \\ ${ }^{1234567)}$ Prodi Perencanaan Wilayah dan Kota, Fakultas Teknik Sipil dan Perencanaan \\ ${ }^{1234567)}$ Institut Teknologi Nasional Malang \\ ${ }^{2)}$ rz.abang@gmail.com
}

\begin{abstract}
Tumpang Subdistrict is one of the sub-districts in Malang Regency which has many steep slopes especially in the east of Tumpang Subdistrict, this area has a high potential for natural disasters, one of which disasters is landslides, so it needs to be repaired. Landslides by tracing the areas that caused landslides in order to minimize losses caused. The purpose of this study is to know the cause and distribution areas which has high potential of landslides. This research method is scoring and weighting, and overlapping with physical digital basic map Tumpang to get areas that use landslides, which are processed using ArcGis 10.2 software. The results of this study are Landslide Prone Maps which are maps that describe areas with the level of landslide vulnerability assessment in the study area. With this result, then it becomes a reference in landslide disaster mitigation to assist the government in diverting landslide disasters in the area
\end{abstract}

Keywords: Map of Prone Landslides, Landslides, Mitigation of Tumpang Subdistrict

\section{Pendahuluan}

\section{Latar Belakang}

Bencana alam adalah suatu kejadian alam yang dapat terjadi setiap waktu. Salah satu kejadian alam yaitu bencana tanah longsor. Tanah longsor yaitu bergeraknya massa tanah atau batuan akibat terjadinya gangguan kestabilan lereng. Faktor yang memicu tanah longsor yang terdapat dua, berupa faktor alami seperti morfologi, struktur geologi, landuse, jenis tanah, struktur geologi, klimatologi (curah hujan) dan kegempaan (Utomo \& Widiatmaka, 2013). Meningkatnya risiko bencana longsor juga terjadi disebabkan karena alih fungsi lahan yang tidak terkontrol karena peningkatan populasi penduduk sehingga diperlukan pengembangan lahan untuk kegiatan permukiman, ekonomi maupun infrastruktur (Priyono \& Priyana, 2006).

Tanah longsor adalah salah satu bencana terbesar ke 3 (tiga) setelah bencana banjir dan puting beliung yang sering terjadi di Indonesia yang mana merupakan negara yang terdapat pertemuan tiga lempeng tektonik aktif yang geografis rawan terjadi bencana alam. Tanah longsor sangat sulit untuk diprediksi dan bisa terjadi kapan saja namun tanah longsor ditimbulkan bukan hanya karena gejala geologi tapi ada ulah campur tangan manusia juga menjadi salah satu pemicu adanya longsoran tanah. Beberapa faktor geologi yang dapat menimbulkan longsoran tanah diantaranya: hujan, tanah yang kurang padat atau kuat, lereng yang terjal, getaran dan tersebarnya zona jenuh air di bawah permukaan.

Adapun faktor-faktor yang menyebabkan tanah longsor adalah: hujan, tanah terjal, tanah yang kurang padat, batuan yang kurang kuat, getaran, surut muka air danau atau bendungan, adanya beban tambahan, pengikisan/erosi, adanya material timbunan pada tebing, bekas longsoran lama, adanya bidang diskontinuitas (bidang tidak sinambung), penggundulan hutan, daerah pembuangan sampah (ESDM 2007).

Bencana tanah longsor pernah terjadi di Desa Duwet Krajan, Tumpang pada Senin 11 Februari 2019 Longsor terjadi akibat curah hujan yang tinggi, Berdasarkan data tim Tagana Kabupaten Malang, sedikitnya 3 rumah warga mengalami kerusakan. Kerusakan nya seperti, rusaknya dapur belakang rumah dan rusaknya pekarangan belakang rumah milik salah satu warga. Namun longsor yang terjadi di Kecamatan Tumpang terjadi dalam skala kecil.

Alasan dari pemilihan lokasi penelitian adalah karena Kecamatan Tumpang terletak di area Kawasan Strategis Nasional Bromo Tengger Semeru (KSN) dimana nantinya akan terjadi perkembangan setiap tahunnya. Selain itu juga Kecamatan Tumpang yang merupakan salah satu daerah yang rawan bencana longsor yang dapat dilihat dari segi morfologi,struktur geologinya dan daerah yang berada di ketinggian 597 meter diatas permukaan laut yang rentan terjadi longsor. Adapun untuk tingkat kerentanan bencana longsor di Kecamatan Tumpang belum diketahui dengan pasti. Ada kemungkinan daerah ini memiliki 
tingkat kerentanan longsor yang tinggi. Maka dari itu peneliti mengambil lokasi kecamatan tumpang untuk mengetahui tingkat keretanan serta adanya pemetaan sebaran daerah-daerah yang rawan terjadi bencana longsor agar nantinya dapat digunakan sebagai acuan dalam suatu perencanaan untuk kedepannya dan kecamatan tumpang rencananya akan menjadi kawasan perkotaan.

Potensi terjadinya tanah longsor yang tinggi di Kecamatan Tumpang diperlukan adanya pemetaan terhadap tanah longsor. Oleh sebab itu untuk meminimalisir terjadinya bencana yang akan menimbulkan kerugian baik berupa materi, harta benda dan keselamatan penduduk sekitar, diperlukan adanya pemetaan bahaya tanah longsor di daerah tersebut untuk mengetahui persebaran potensi tanah longsor. Adapun pemetaan potensi tanah longsor diolah menggunakan software pemetaan, salah satunya adaalaah software ArcGis, dengan menggunakan parameter-parameter yang digunakan dalam pemetaan bencana longsor.

\section{Rumusan Masalah}

Adapun rumusan masalah dalam penelitian ini adalah:

a) Bagaimana tingkat kerentanan bencana longsor di Kecamatan Tumpang Kabupaten Malang?

b) Dimana sebaran daerah yang rentan terjadi bencana longsor di Kecamatan Tumpang Kabupaten Malang?

\section{Tujuan Penelitian}

Penelitian ini bertujuan untuk mengidentifikasi dan menganalisis daerah rawan bencana longsor di Kecamatan Tumpang Kabupaten Malang.

\section{Metode Penelitian}

\section{Lokasi Penelitian}

Pada penelitian ini daerah penelitian mencakup 1 kecamatan di Kabupaten Malang yaitu Kecamatan Tumpang, Kecamatan ini terdiri dari 15 Desa, 41 Dusun, 109 RW, dan 659 RT. Ke-15 desa di kecamatan ini adalah Desa Tumpang, Malangsuko, Jeru, Wringinsongo, Bokor, Slamet, Kidal, Kambinan, Ngingit, Pandanajeng, Pulungdowo, Tulusbesar, Benjor, Duwet dan Duwetkrajan. Kecamatan Tumpang dikelilingi oleh kecamatan lainnya yang ada di Kabupaten Malang. Di sebelah utara, Kelurahan Tumpang berbatasan langsung dengan Kecamatan Jabung. Sedangkan di sebelah timur, kecamatan ini berbatasan langsung dengan Pegunungan Bromo Semeru. Di sebelah selatan, Kecamatan Tumpang berbatasan dengan Kecamatan
Poncokusumo. Lalu, di sebelah barat, kecamatan ini berbatasan dengan Kota Malang.

\section{Metode Pengumpulan Data}

Metode yang dilakukan dalam penelitian dapat dilakukan dengan survei primer dan survei sekunder.

a. Survei Primer

Survei Primer adalah metode yang dilakukan secara langsung di lapangan sehingga memperoleh gambaran eksisiting pada wilayah tersebut, berupa informasi dan data primer yang berkaitan dengan kondisi fisik eksisting. Metode ini dilakukan melalui wawancara, observasi dan kuisioner.

i. Wawancara

Menurut Prabowo (1996) wawancara adalah metode pengambilan data dengan cara menanyakan sesuatu kepada seseorang responden, caranya adalah dengan bercakap cakap secara tatap muka. Pada penelitian ini wawancara akan dilakukan dengan menggunakan pedoman wawancara. Dalam hal ini informasi yang dibutuhkan dengan menanyakan langsung kepada narasumber yang ada di lokasi penelitian.

ii. Observasi

Menurut Nawawi \& Martini (1991) observasi adalah pengamatan dan pencatatan secara sistimatik terhadap unsur-unsur yang tampak dalam suatu gejala atau gejala-gejala dalam objek penelitian. Metode ini digunakan dengan turun langsung ke lapangan untuk melihat kondisi eksisting (sebenarnya) di lokasi penelitian yaitu survei fisik yang mencakup semua penelitian-penelitian yang akan dituangkan di dalam peta.

\section{iii. Kuisioner}

Kuesioner merupakan suatu teknik pengumpulan data secara tidak langsung (peneliti tidak langsung bertanya jawab dengan responden). Instrumen atau alat pengumpulan datanya juga disebut angket berisi sejumlah pertanyaan-pertanyaan yang harus dijawab atau direspon oleh responden. Responden mempunyai kebiasaan untuk memberikan jawaban atau respon sesuai dengan presepsinya. Dilakukan dengan menyebarkan angket pertanyaan mengenai aspek-aspek yang diteliti sesuai dengan topik permasalahan apa yang diambil dalam penelitian.

\section{b. Survei Sekunder}

Dalam survei sekunder, yang dilakukan adalah mencari dan mengumpulkan data - data sekunder yang tersedia pada dinas atau instansi terkait. Data sekunder sendiri berisikan tentang buku, tabulasi data, artikel, laporan dan sumbersumber lain yang dapat mendukung kegiatan penelitian 


\section{Data yang Digunakan}

Data spasial dalam SIG dipresentasikan dalam dua format, yaitu format spasial dan format raster. Data spasial itu sendiri merupakan data yang bersifat keruangan. Data yang telah dikumpulkan sebelumnya dalam format spasial berupa peta analog, yaitu peta parameter. Berikut data spasial yang digunakan dalam penelitian ini.

a) Citra DEM Kecamatan Tumpang

b) Citra Landsat 8 Kecamatan Tumpang

c) Data curah hujan harian Kecamatan Tumpang

d) Peta Geologi Digital Kecamatan Tumpang

Peta Jenis Tanah Digital Kecamatan Tumpang

\section{Pengolahan Data}

Pengolahan data pada penelitian ini terdiri dari beberapa proses untuk mendapatkan parameter-parameter penyebab tanah longsor. Peta jenis tanah, geologi dan tutupan lahan berupa shapefile dilakukan clip pada daerah penelitian. Pengolahan curah hujan dilakukan dengan membuat Poligon Thiessen dari 9 stasiun penakar curah hujan di daerah penelitian. Metode Thiessen merupakan metode yang ditentukan dengan cara membuat poligon antar stasiun pada suatu wilayah. Setelah area ditentukan kemudian menghitung curah hujan tahunan dari data tabular curah hujan harian.

Pengolahan Landsat 8 dilakukan klasifikasi supervised yang dikelaskan menjadi 6 kelas tutupan lahan yaitu hutan, sawah, semak, pemukiman, kebun dan tanah kosong. Kemudian hasil klasifikasi dilakukan uji ketelitian dengan keadaan dilapangan. Pengolahan DEM dilakukan untuk mendapatkan kemiringan lereng, DEM diekstrak menjadi kontur dan kemiringan. Kemiringan DEM dikelaskan menjadi 5 kelas. Kemiringan ekstraksi DEM data berupa raster karena itu harus diubah menjadi data shapefile dengan cara reclassify untuk mendapatkan info table kemiringan kemudian dilakukan convert raster to polygon. Setelah diperoleh parameter parameter tanah longsor kemudian dilakukan pemberian skor pada masing-masing kelas dan bobot pada masing-masing parameter kemudian dioverlaykan. Analisa daerah potensi rawan banjir dan longsor didasarkan pada nilai total skor pada masing-masing area. Penetapan tingkat kerawanan daerah kejadian longsor di daerah penelitian didasarkan kepada model pendugaan kawasan rawan tanah longsor oleh Direktorat Vulkanologi dan Mitigasi Bencana Geologi/DVMBG (2004). Skor $=(30 \% \mathrm{x}$ faktor kelas curah hujan $)+(20 \% \mathrm{x}$ geologi $)+(20 \% \mathrm{x}$ faktor kelas jenis tanah $)+(15 \% \mathrm{x}$ penggunaan lahan $)+(15 \% \mathrm{x}$ faktor kelas lereng $)$
Tabel 1. Parameter Pembobotan Tanah Longsor Parameter Besaran Skor Bobot

\begin{tabular}{|c|c|c|c|}
\hline Parameter & Besaran & Skor & Bobot \\
\hline \multirow{5}{*}{ Kemiringan } & $<8 \%$ & 1 & \multirow{5}{*}{$15 \%$} \\
\hline & $8-15 \%$ & 2 & \\
\hline & $15-25 \%$ & 3 & \\
\hline & $25-45 \%$ & 4 & \\
\hline & $>45 \%$ & 5 & \\
\hline \multirow{5}{*}{$\begin{array}{l}\text { Curah Hujar } \\
\text { Tahunan } \\
\text { (mm/tahun) }\end{array}$} & $<1000$ & 1 & \multirow{5}{*}{$30 \%$} \\
\hline & $1000-2000$ & 2 & \\
\hline & $2000-2500$ & 3 & \\
\hline & $2500-3000$ & 4 & \\
\hline & $>3000$ & 5 & \\
\hline \multirow{5}{*}{ Jenis Tanah } & Tidak peka & 1 & \multirow{5}{*}{$20 \%$} \\
\hline & Agak peka & 2 & \\
\hline & Kurang peka & 3 & \\
\hline & Peka & 4 & \\
\hline & Sangat peka & 5 & \\
\hline \multirow{6}{*}{ Geologi } & Bahan Alluviaal & 1 & \multirow{6}{*}{$20 \%$} \\
\hline & Bahan Vulkanik 1 & 2 & \\
\hline & Bahan Sedimen 1 & 3 & \\
\hline & $\begin{array}{l}\text { Bahan Sedimen } 2 \\
\text { Vulkanik } 2 \\
\end{array}$ & 4 & \\
\hline & $\begin{array}{l}\text { Hutan/vegetasi lebat } \\
\text { dan badan air }\end{array}$ & 1 & \\
\hline & $\begin{array}{l}\text { Kebun dan campuran } \\
\text { semak belukar }\end{array}$ & 2 & \\
\hline \multirow{3}{*}{$\begin{array}{l}\text { Tutupan } \\
\text { Lahan }\end{array}$} & $\begin{array}{l}\text { Perkebunan dan } \\
\text { sawah irigasi }\end{array}$ & 3 & \multirow{3}{*}{$15 \%$} \\
\hline & $\begin{array}{l}\text { Kawasan industri dan } \\
\text { pemukiman }\end{array}$ & 4 & \\
\hline & Lahan-lahan kosong & 5 & \\
\hline
\end{tabular}

Sumber: Hasil Analisa 2020

\section{Hasil dan Pembahasan}

\section{Curah Hujan}

Data curah hujan yang di dapatkan untuk kecamatan tumpang yang dilakukan pengolahan dengan menggunakan arcgis. Daerah curah hujan pada daerah penelitian berkisar antara 1.750-2250 mm/tahun. Peta persebaran kelas curah hujan pada daerah penelitian dapat dilihat pada gambar di bawah.

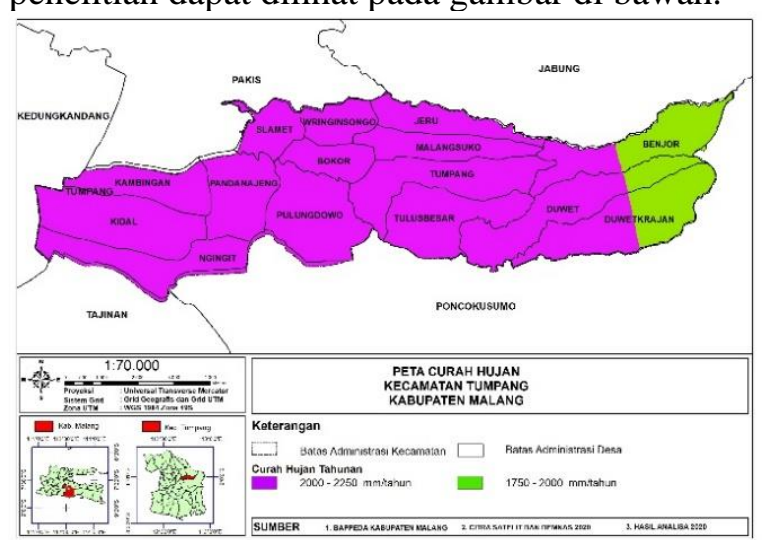

Gambar 3. Curah Hujan di Kecamatan Tumpang, Kabupaten Malang

Sumber: Hasil Analisa 2020

Pada peta diatas curah hujan digolongkan menjadi 2 kelas dimana kelas pertama yaitu $1.750-2000 \mathrm{~mm} /$ tahun dan kelas yang kedua 
yaitu $2000-2250 \mathrm{~mm} / \mathrm{tahun}$. Dari peta diatas dapat dilihat bahwa daerah yang berada di bagian barat memiliki curah hujan yang cukup tinggi.

\section{Jenis Tanah}

Data Jenis tanah yang berada di kecamatan tumpang didapatkan terdapat 3 jenis tanah yang berada di dearah penelitian yaitu andosol, litosol, dan non cal. Berikut merupakan peta jenis tanah kecamatan tumpang.

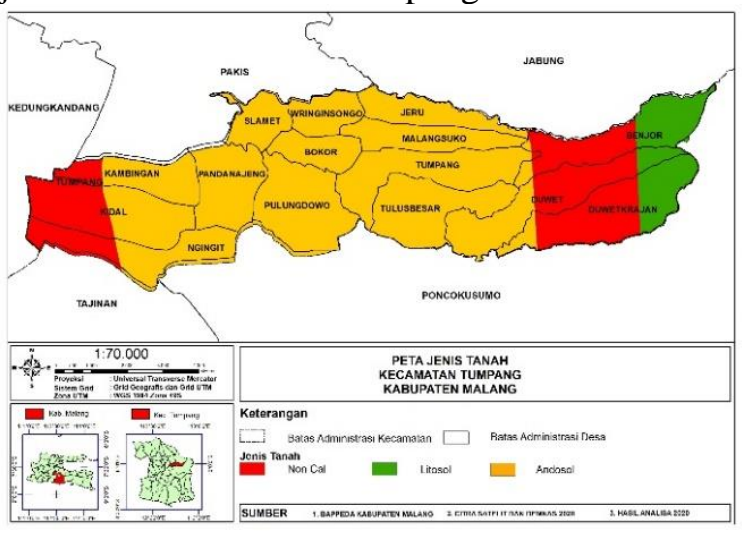

Gambar 4. Jenis Tanah di Kecamatan Tumpang, Kabupaten Malang

Sumber: Hasil Analisa 2020

Dari peta diatas dapat dilihat bahwa daerah yang berada di tengah kecamatan tumpang memiliki jenis tanah andosol. Dimana tanah ini merupakan tanah yang tergolong cukup rawan terjadi longsor.

\section{Penggunaan Lahan}

Dari dapat yang didapat untuk penggunaan lahan untuk kecamatan tumpang terbagi menjadi 6 klasifikasi yaitu permukiman, agrikultural lading, perkebunan, non agrikultur alang sabana padang, non agrikultur hutan lahan kering dan non agrikultur semak belukar. Dapat dilihat pada peta dibawah berikut.

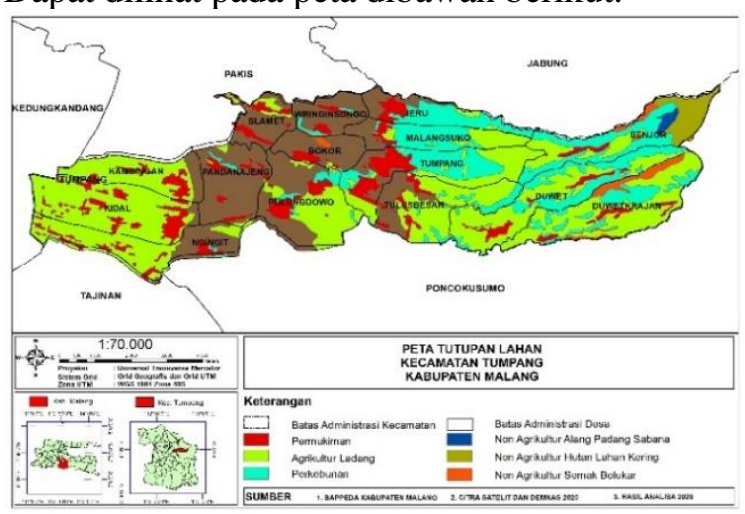

Gambar 5. Penggunaan Lahan di Kecamatan Tumpang, Kabupaten Malang

Sumber: Hasil Analisa 2020

Dari peta diatas dapat dilihat bahwa pada bagian barat daerah penelitian cukup jarang terdapat kawasan permukiman

\section{Geologi}

Data untuk geologi untuk kecamatan tumpang terbagi menjadi 2 jenis batuan yaitu batuan gunung api plistosen dan batuan tuf plistosen, karena kecamatan ini berada di daerah pegunungan. Berikut merupakan peta geologi daerah penelitian.

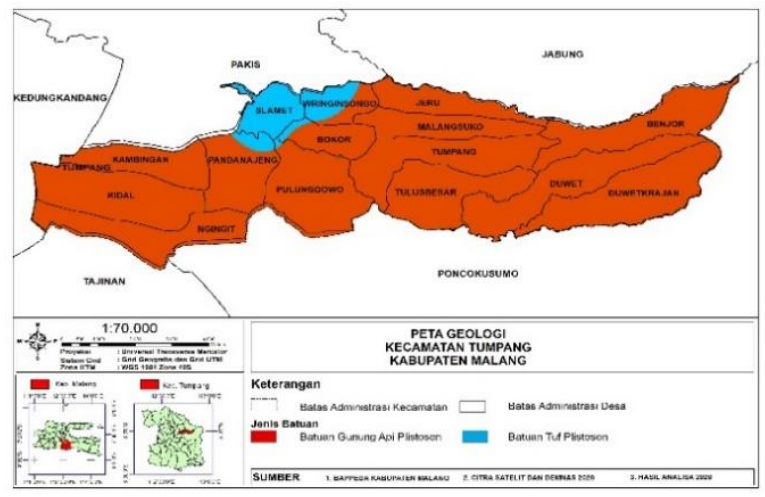

Gambar 6. Geologi di Kecamatan Tumpang, Kabupaten Malang

Sumber: Hasil Analisa 2020

\section{Kelerengan}

Data kelerangan pada kecamatan tumpang sangat bervariasi dimana dibagi menjadi 5 kelas yaitu $0-8 \%, 8-15 \%, 15-25 \%, 25-45 \%$, dan $45 \%$ > berikut merupakan peta kelerengan daerah penelitian.

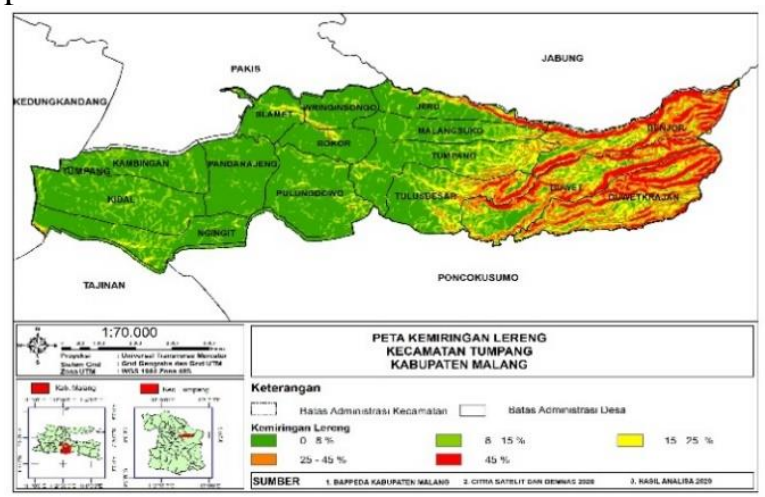

Gambar 7. Kemiringan Lereng di Kecamatan Tumpang, Kabupaten Malang

Sumber: Hasil Analisa 2020

Dari peta diatas dapat dilihat bahwa daerah yang berada disebalah timur memiliki kelerengan yang lebih dari $45 \%$ dimana daerah tersebut cukup dekat dengan lereng gunung bromo sedangkan daerah di sebelah barat memiliki kelerang yang cukup datar.

\section{Daerah Rawan Longsor}

Data daerah rawan longsor didapat dari hasil skoring yang didapat dari semua parameter untuk menentukan daerah yang merupakan daerah rawan longsor dan dapat diketahui bahwa parameter yang paling berpengaruh terhadap terjadinya bencana tanah longsor adalah jumlah curah hujan sehingga proporsi nilainya lebih tinggi dari pada parameter lainnya untuk menentukan daerah rawan 
longsor. Berikut merupakan peta daerah rawan longsor yang berada di kecamatan tumpang.

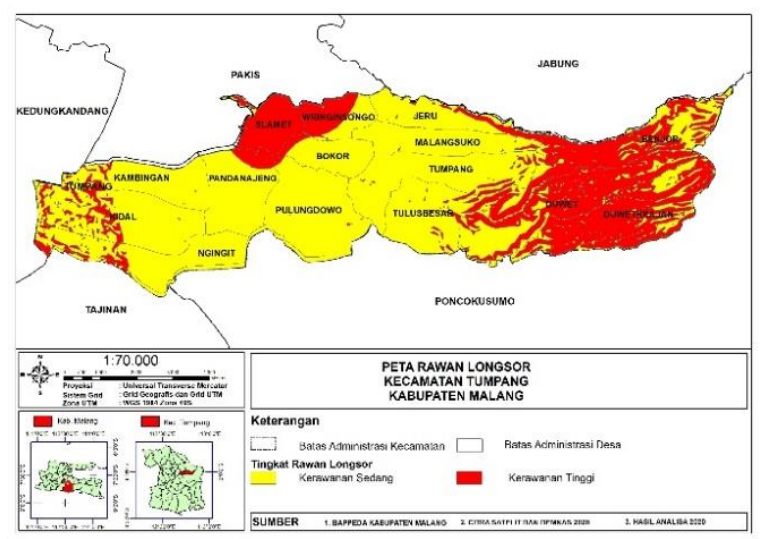

Gambar 8. Derah Rawan Longsor di Kecamatan Tumpang, Kabupaten Malang

Sumber: Hasil Analisa 2020

Dapat dilihat dari peta diatas daerah sebelah barat tergolong daerah yang memiliki tingkat kerawanan longsor sedang berbeda dengan daerah yang berada disebelah timur yang memiliki tingkat rawan longsor yang tinggi dimana pada daerah tersebut banyak sekali terdapat kawasan yang sangat curam serta termasuk dalam kawasan lereng gunung bromo, karena itulah daerah Kecamatan Tumpang yang berada di sebelah timur memiliki tingkat kerawanan longsor sangat tinggi.

Tabel 2. Daerah Rawan Longsor

\begin{tabular}{|l|l|l|}
\hline \multirow{2}{*}{ Desa } & $\begin{array}{l}\text { Luas Tingkat } \\
\text { Longsor (Ha) }\end{array}$ & \multicolumn{2}{l|}{ Kerawanan } \\
\cline { 2 - 3 } & Sedang & Tinggi \\
\hline Bokor & 185,94 & 19,86 \\
\hline Pulungdowo & 525,08 & 5,73 \\
\hline Wringinsongo & 82,56 & 111,66 \\
\hline Tumpang & 505,99 & 34,59 \\
\hline Malangsuko & 304,31 & 4,47 \\
\hline Pandanajeng & 343,07 & 45,85 \\
\hline Slamet & 4,21 & 191,13 \\
\hline Duwetkrajan & 143,22 & 493,94 \\
\hline Duwet & 189,51 & 398,95 \\
\hline Benjor & 164,86 & 338,07 \\
\hline Tulusbesar & 400,42 & 86,59 \\
\hline Jeru & 223,57 & 39,38 \\
\hline Ngingit & 373,77 & 42,01 \\
\hline Kidal & 509,57 & 85,72 \\
\hline Kambingan & 305,40 & 18,11 \\
\hline Total & 4261,49 & 1916,05 \\
\hline
\end{tabular}

Sumber: Hasil Analisa 2020

Terdapat 4 dusun dikecamatan tumpang yang termasuk daerah rawan longsor yaitu Dusun Duwet, Dusun Duwet Krajan, Dusun Benjor, dan Dusun Slamet dimana daerah 3 dusun berada di sebelah timur kecamatan tumpang dan 1 dusun berada di sebelah utara Kecamatan Tumpang.

\section{Hasil Wawancara}

a. Wawancara 1 Hari/tanggal: Kamis, 12 maret 2020 Waktu: 11.40

Lokasi: Kantor Desa Duwet Krajan (Dusun Swaru)

Nama Narasumber: Pak Imam Taufik

Pekerjaan: Kepala Dusun

- Terjadi bencana tanah longsor skala kecil di Dusun Swaru, Krajan, Tosari.

- Pernah terjadi longsor skala kecil di dusun tosari tahun 2020 dan terjadi awal musim hujan

- Ada bantuan dri BPBD, kepolisian, dari warga gotong royong.

- Jenis tanah gembur

- Longsor sering terjadi saat musim hujan

- Penyebab terjadinya bencana longsor karena adanya waktu hujan yang cukup lama

- Sudah terdapat jalur evakuasi langsung ada rencana ada setiap jangka panjang

- Pembuatan sak sak (karung diisi sesuatu) disusun (PPT) untuk sebagai pondasi tanah di setiap bangunan rumah yang di fasilitasi oleh pemerintah

- Untuk Rumah tunggal yang di buat pribadi

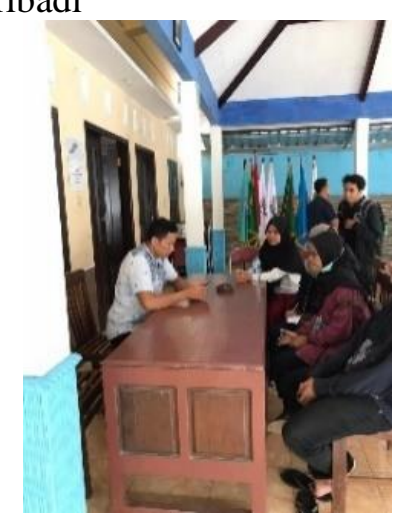

Gambar 9. Wawancara Kepala Dusun Swaru, Desa Dawet

Sumber: Hasil Analisa 2020

b. Wawancara 2

Hari/tanggal: Kamis, 12 maret 2020

Waktu: 11.25

Lokasi: Desa Duwet Krajan

Nama Narasumber: Pak Samsul

Pekerjaan: Petani

- Belum pernah terjadi bencana longsor skala besar di sekitar tempat tinggal pak samsul. 
- Tanah longsor terjadi hanya dalam skala kecil biasanya terjadi di pekarangan rumah saja

- Sering terjadi kebakaran hutan di sekitar kawasan Bromo

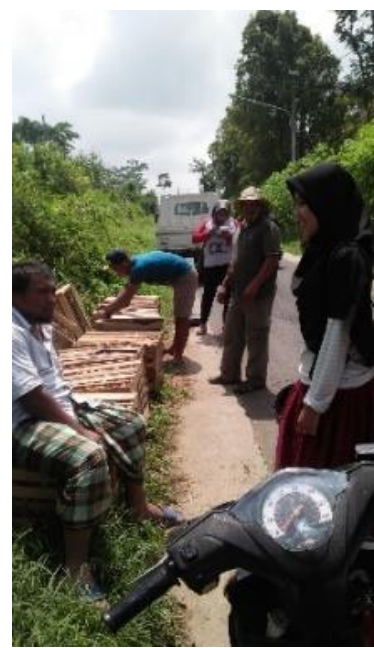

Gambar 8. Wawancara Masyarakat Setempat Sumber: Hasil Analisa 2020

c. Wawancara 3

Hari/tanggal: Kamis, 12 maret 2020

Waktu: 12.05

Lokasi: Dusun Tosari

Nama Narasumber: Pak Bagus

Pekerjaan: Petani

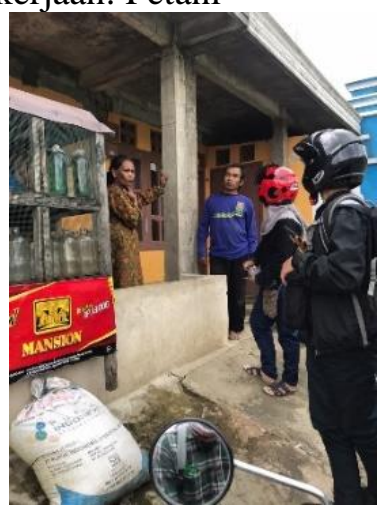

Gambar 9. Wawancara Masyarakat Setempat Sumber: Hasil Analisa 2020

- Terjadi bencana longsor skala kecil di dusun tosari

- Hanya terdampak pada satu rumah saja

- Longsor terjadi karena hujan yang cukup lama

- Jika terjadi bencana longsor akan dibantu langsung oleh BPBD Kabupaten Malang dan gotong royong dari warga sekitar.

d. Wawancara 4

Hari/tanggal: Kamis, 12 maret 2020

Waktu: 12.05

Lokasi: Dusun Tosari

Nama Narasumber: Pak Tejo

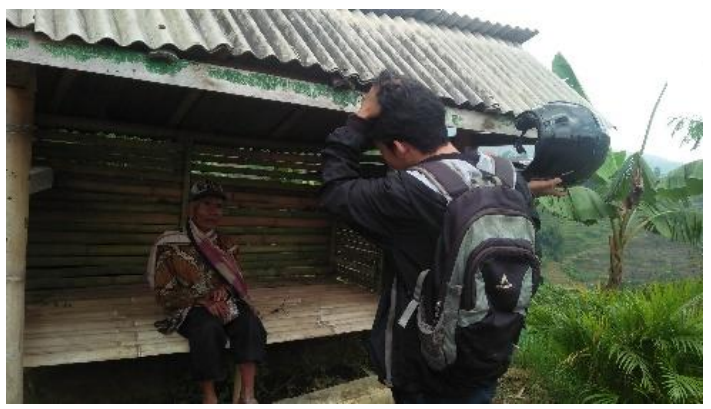

Gambar 10. Wawancara Masyarakat Setempat Sumber: Hasil Analisa 2020

- Jarang terjadi bencana longsor

- bencana longsor terjadi jika waktu hujan yang cukup lama

- Jika terjadi bencana maka perangkat desa akan langsung melaporkan ke polisi untuk meminta bantuan ke BPBD

- Longsor sering terjadi di perkebunan warga saja

- Pernah terjadi longsor yang membuat jalan di desa hancur

\section{Kesimpulan}

Adapun beberapa hal yang bisa disimpulkan dari penelitian ini adalah:

1. Daerah kecamatan tumpang sebelah timur merupakan daerah yang memiliki potensi rawan tanah longsor dikarenakan morfologi daerah tersebut yang curam serta termasuk dalam kawasan lereng gunung bromo, karena itulah daerah kecamatan tumpang yang berada di bagian timur memiliki tingkat kerawanan longsor sangat tinggi.

2. Dari data jenis tanah yang berada di kecamatan tumpang didapatkan terdapat 3 jenis tanah yang berada di dearah penelitian yaitu andosol, litosol, dan non cal. Jenis tanah di beberapa desa yang ada di kecamatan tumpang merupakan jenis tanah andosol. dimana tanah ini merupakan tanah yang tergolong cukup rawan terjadi longsor,

3. Dari data geologi untuk Kecamatan Tumpang terbagi menjadi 2 jenis batuan yaitu batuan gunung api plistosen dan batuan tuf plistosen, karena kecamatan ini berada di daerah pegunungan.

4. Terdapat 4 dusun di Kecamatan Tumpang yang memiliki luasan daerah terbesar untuk daerah rawan longsor dengan tingkat kerawanan tinggi yaitu dusun duwet yang memiliki luasan daerah rawan longsor sebesar 398,95 Ha, dusun duwet krajan sebesar 493,94 $\mathrm{Ha}$, dusun benjor sebesar 338,07 Ha, dan dusun slamet sebesar 191,13 Ha, dimana 3 dusun berada di sebelah timur Kecamatan Tumpang dan 1 dusun 
berada di sebelah utara kecamatan tumpang.

5. Terdapat 5 dusun di Kecamatan Tumpang yang memiliki luasan terbesar untuk daerah rawan longsor dengan tingkat kerawanan sedang yaitu dusun pulungdowo yang memiliki luasan daerah rawan longsor sebesar $525,08 \mathrm{Ha}$, dusun tumpang sebesar 505,99 $\mathrm{Ha}$, dusun tulusbesar sebesar 400,42 Ha, dan dusun tulusbesar sebesar 509,57 Ha

\section{Ucapan Terimakasih}

Ucapan terimakasih disampaikan kepada Program Studi Perencanaan Wilayah dan Kota Institut Teknologi Nasional Malang, yang telah memberikan kesempatan serta bimbingan kepada kami untuk melakukan kajian ilmiah terkait penentuan zona daerah rawan bencana longsor di Kecamatan Tumpang, Kabupaten Malang

\section{Daftar Pustaka}

1) Taufik Dr. Ir. M. Kurniawan Akbar, Rohmah Alfi. (2016). Identifikasi Daerah Rawan Tanah Longsor Menggunakan SIG (Sistem Informasi Geografis) (Studi Kasus: Kabupaten Kediri) ISSN: 2337-3539.

2) Sutasoma Muwardi, Susilo Adi, Suryo Eko Andi. (2017). Penyelidikan Zona Longsor dengan Metode Resistivitas dan Analisis Stabilitas Lereng untuk Mitigasi Bencana Tanah Longsor (Studi Kasus di Dusun Jawar, Desa Sri Mulyo, Kecamatan Dampit, Kabupaten Malang, Provinsi Jawa Timur), ISSN:2089 - 0133.

3) Khafid, Mohammad Abdul, (2019). Analisis Penentuan Zonasi Pemukiman Risiko Bencana Tanah Longsor Berbasis Sistem Informasi Geografis: Studi Kasus Kecamatan Gedangsari, Kabupaten Gunungkidul, Daerah Istimewa Yogyakarta

4) Anastasia Dewi Titisari, Hitznaiti Zaidini Khul Husna, Ilham Dharmawan Putra, I Gde Budi Indrawan, (2019). Penentuan Zona Kerentanan Longsor Berdasarkan Karakteristik Geologi dan Alterasi Batuan, 141 - 158.

5) Bayuaji, Dhuha Ginanjar, Nugraha Arief Laila, (2016). Analisis Penentuan Zonasi Risiko Bencana Tanah Longsor Berbasis Sistem Informasi Geografis (Studi Kasus: Kabupaten Banjarnegara).

6) Bahrudin, Muhammad Joko Umbaran Haris, (2018). Zonasi Daerah Rawan Longsor Menggunakan Analisis Sistem
Informasi Geografis Berdasarkan Metode AHP Pada Daerah Gunung Kidul Yogyakarta.

7) Nasiah \& Invanni Ichsan, (2014). Identifikasi Daerah Rawan Bencana Longsor Lahan Sebagai Upaya Penanggulangan Bencana di Kabupaten Sinjai, ISSN 2086-6755.

8) Riyanto, Muhammad Zaki, (2019). Studi Pendahuluan Penentuan Zonasi Kerentanan Gerakan Tanah di Kawasan Desa Binaan UIN Sunan Kalijaga di Kecamatan Kalibawang, Kabupaten Kulon Progo, D.I. Yogyakarta

9) Mulyaningsih, Sari \& Setiadi Tedy, (2014). Sistem Informasi Geografis Pemetaan Daerah Rawan Tanah Longsor Di Kabupaten Gunung Kidul Berbasis Web, e-ISSN 2338-5197

10) Handayani, Linda \& Singarimbun, Alamta, (2016). Pemetaan Daerah Rawan Longsor Di Sekitar Daerah Prospek Panas Bumi Provinsi Jawa Barat, ISSN 2502-2016.

11) Hamida, Fakhryza Nabila \& Widyasamratri, Hasti, (2019). Risiko Kawasan Longsor Dalam Upaya Mitigasi Bencana Menggunakan Sistem Informasi Geografis.

12) Bayuaji, Dhuha Ginanjar \& Nugraha, Arief Laila, Sukmono, Abdi, (2016). Analisis Penentuan Zonasi Risiko Bencana Tanah Longsor Berbasis Sistem Informasi Geografis (Studi Kasus: Kabupaten Banjarnegara).

13) Subhan, Murtilaksono, \& Barus, (2019). Identifikasi Dan Analisis Karakteristik Longsor Di Kabupaten Garut, e-ISSN 2502-5295.

14) Nasiah, \& Invanni, Ichsan, (2013). Zonasi Daerah Rawan Bencana Longsor Di Sulawesi Selatan.

15) Anastasia Dewi Titisari, Hitznaiti Zaidini' Khul Husna, Ilham Dharmawan Putra, \& I Gde Budi Indrawan, (2019). Penentuan Zona Kerentanan Longsor Berdasarkan Karakteristik Geologi dan Alterasi Batuan, 141 - 158 